\title{
Pregabalin to improve postoperative recovery in bariatric surgery: a parallel, randomized, double- blinded, placebo-controlled study
}

This article was published in the following Dove Press journal: Journal of Pain Research

\author{
Marcelo J Martins' \\ Caroline Paiva Matos \\ Oliveira Martins ${ }^{2}$ \\ Lucas J Castro-Alves ${ }^{3}$ \\ Gabriel Nascimento Jesus ${ }^{4}$ \\ Guilherme Oliveira \\ Campos $^{5}$ \\ Breno Barbosa Cerqueira \\ Sacramento ${ }^{4}$ \\ Leonardo Ferrari Borges 6 \\ Carlos Augusto Bastos \\ Mello ${ }^{6}$ \\ Rodrigo Leal Alves ${ }^{5}$ \\ Norma Sueli Pinheiro \\ Módolo7
}

'Department of Anesthesiology, São Paulo State University (UNESP),

São Paulo, Brazil; ${ }^{2}$ Department of Anesthesiology at Federal University of Bahia, Bahia, Brazil; 'Department of Anesthesiology, Santo Antonio Hospital, Salvador, Bahia, Brazil; ${ }^{4}$ Department of Anesthesia, Bahia University of Medicine and Public Health, Bahia, Brazil, ${ }^{5}$ Department of Anesthesiology, Hospital Sao Rafael, Salvador, Bahia, Brazil; ${ }^{6}$ Department of Surgery, Hospital Tereza de Lisieux, Salvador, Bahia, Brazil; ${ }^{7}$ Department of Anaesthesiology, São Paulo State University (UNESP), Botucatu, Brazil

Correspondence: Marcelo J Martins Department of Anesthesiology, University of Medicine of Botucatu, Rubiao Jr. District, mailbox 530, Botucatu |86|8-970, Brazil

Tel +55 7l 99l393736

Email celoufba@yahoo.com.br
Purpose: Obesity has been considered as a major public health problem in developed countries for which bariatric surgery has become an important treatment strategy. Postoperative pain, however, is a frequent problem in postoperative management. Pregabalin blocks the development of hyperalgesia and central pain sensitization. The objective of this randomized, placebo-controlled, double-blinded trial was to evaluate the effect of a single dose of preoperative pregabalin vs placebo on the quality of postoperative recovery in patients undergoing bariatric surgery.

Patients and methods: A total of 70 patients undergoing abdominal gastroplasty were randomly assigned to receive oral pregabalin $(75 \mathrm{mg})$ or an identical placebo 1 hour before surgery. The primary outcome was Quality of Recovery-40 (QoR-40) score at 24 hours. Secondary outcomes included opioid consumption and postoperative pain scores. $P<0.05$ was considered to indicate statistical significance.

Results: In all, 60 of the 70 patients completed the study. The mean (SD) global recovery scores (QoR-40) 24 hours after surgery in the pregabalin and control groups were 183.7 (9) and 182.1 (12), respectively (mean difference $=1.6,95 \% \mathrm{CI}-7.36$ to $4.2, P=0.59$ ). There was no significant difference in the total opioid consumption in the 24 hours following surgery between the two groups (pregabalin vs control $=0.47 \times 0.2$; mean difference $=0.26,95 \% \mathrm{CI}-0.24$ to $0.77, P=0.3$ ). There were no significant differences in nausea, vomiting, or time to postanesthesia care unit discharge between the two groups.

Conclusion: In patients who underwent bariatric surgery, a single preoperative dose of pregabalin $(75 \mathrm{mg}$ ) did not improve pain relief, quality of postoperative recovery, or reduction in opioid consumption.

Clinical trial registration: http://www.ensaiosclinicos.gov.br (identifier: RBR-2g89x8).

Keywords: gastroplasty, hyperalgesia, opioid

\section{Introduction}

The prevalence of overweight patients has increased rapidly in recent decades and is currently considered a global epidemic. Obesity is associated with several comorbidities, including high blood pressure and diabetes, which reduce the life expectancy of these patients. Considering these aspects, guidelines were established for the surgical therapy of morbid obesity (body mass index [BMI] $\geq 40 \mathrm{~kg} / \mathrm{m}^{2}$ or BMI $\geq 35 \mathrm{~kg} / \mathrm{m}^{2}$ in the presence of comorbidities). ${ }^{1}$ Considering that the number of bariatric surgical procedures has dramatically increased since these guidelines were established, attention to postoperative pain control in these patients has become more evident. ${ }^{2,3}$ Although opioids continue to have an important role in postoperative pain management, they 
are not free of side effects, and a multimodal approach has been suggested to improve postoperative analgesia while mitigating these side effects. ${ }^{4,5}$

Pregabalin is a structural analog of the gamma-aminobutyric acid (GABA) neurotransmitter that binds to the alpha-2-subunit of the voltage-dependent calcium channel, blocking the development of hyperalgesia and central pain sensitization. ${ }^{6}$ Pregabalin alters calcium currents and reduces or modulates the release of various excitatory neurotransmitters, producing inhibitory modulation of "overexcited" neurons and returning them to a "normal" state. ${ }^{7}$ Recent placebo-controlled studies suggest that pregabalin also has a significant analgesic effect on acute postoperative pain. ${ }^{4,8,9}$

The objective of the present randomized clinical trial was to investigate the effects of a single preoperative dose of pregabalin on the global postoperative quality of recovery after bariatric surgery. To the best of our knowledge, this is the first study to evaluate the use of preoperative pregabalin using the Quality of Recovery-40 (QoR-40) questionnaire. The hypothesis of the present study was that individuals who received preoperative pregabalin would exhibit better-quality recovery 24 hours after surgery than those who received placebo. In addition, we sought to assess whether perioperative pregabalin had opioid-sparing properties when administered as part of a multimodal pain strategy.

\section{Patients and methods}

This study was a parallel, randomized, double-blinded, placebo-controlled trial. Ethics approval was obtained from the institutional review board of Santo Antonio Hospital. The study is described in accordance with the CONSORT. This clinical trial was registered at http://www.ensaiosclinicos. gov.br (identifier: RBR-2g89x8). Trial registration occurred before the first patient was randomized, and no changes were made to the primary outcome after the initial trial registration. After written informed consent was obtained, 70 patients (18-64 years of age) undergoing bariatric surgery (non-laparoscopic surgery), with American Society of Anesthesiologists (ASA) physical classes I-III, were randomized and included in the study. Subjects were excluded if they were allergic to pregabalin; unable to understand the nature of the study and, therefore, could not provide informed consent; had renal and/or liver disease; or were taking chronic opioids and/ or antidepressants. Reasons for exclusion after randomization included protocol violations or surgeon/patient request. Subjects were randomly assigned using a computer-generated table of random numbers to receive either pregabalin $75 \mathrm{mg}$ or a placebo pill, both administered orally 1 hour before surgery. The capsules for each group were sealed in opaque envelopes numbered according to the randomization table generated by the computer software and opened after inclusion of the patient in the study. The study was conducted in only one hospital, and the surgical team was the same during the period of the clinical trial.

After arrival to the operating room, standard ASA monitors were applied. All patients underwent general anesthesia after adequate positioning and preoxygenation. Anesthetic induction was performed using propofol (2 mg/ $\mathrm{kg}$ ideal body weight [IBW]), sufentanil (0.5 $\mu \mathrm{g} / \mathrm{kg}$ IBW), and rocuronium $(0.5 \mathrm{mg} / \mathrm{kg} \mathrm{IBW})$. General anesthesia was maintained followed by volatile anesthetic (sevoflurane, one minimum alveolar concentration) maintenance. All subjects received dexamethasone $4 \mathrm{mg}$ at the beginning of surgery and ondansetron $4 \mathrm{mg}$ at the end of surgery to prevent postoperative nausea and/or vomiting (PONV). Intraoperative analgesia included intravenous (IV) administration of $2 \mathrm{~g}$ dipyrone (metamizol) associated with $100 \mathrm{mg}$ of ketoprofen, in addition to $0.1 \mathrm{mg} / \mathrm{kg}$ IBW of morphine. The wound was infiltrated with local anesthetic (bupivacaine 0.25\%, $20 \mathrm{~mL}$ ) at the end of surgery.

In the postanesthetic care unit (PACU), subjects were assessed for pain on arrival and at regular intervals of 15 minutes using a numerical rating scale (NRS; scored from 0 to 10 , in which $0=$ no pain and $10=$ the worst pain imaginable). The scores were assessed with patients at rest and after asking them to cough. Morphine sulfate (1-2 mg IV) was administered every 15 minutes to maintain an NRS pain score $<4$ ( $1 \mathrm{mg}$ for pain $<7 / 10$ and $2 \mathrm{mg}$ for pain $\geq 7 / 10)$. The incidence of nausea was assessed at the same intervals and recorded as either present or absent. The number of episodes of vomiting was also recorded. The PACU discharge was performed using the modified Aldrete scale every 15 minutes until the patients met discharge criteria (score $\geq 9$ ). PONV was treated with $10 \mathrm{mg}$ of metoclopramide IV.

Pain assessments were performed by the nurses on the ward every 4 hours. Postoperatively, patients received ketoprofen $100 \mathrm{mg}$ IV every 8 hours and metamizol 2 g IV every 6 hours. Morphine sulfate at doses of 1-2 mg IV was used as needed to maintain an NRS pain index $<4$ ( $1 \mathrm{mg}$ for pain $<7 / 10$ and $2 \mathrm{mg}$ for pain $\geq 7 / 10$ ).

The following perioperative data were collected: age, height, weight, ASA physical status, duration of surgery, total IV fluids, pain at rest and after cough score, and total amount of morphine in the PACU and in the 24 hours after surgery. The perioperative data were collected by researchers who were not involved with patient care and blinded to the 
allocation of study groups. The QoR-40 was completed by the subjects 24 hours after the surgical procedure (Figure S1). ${ }^{10,11}$ The QoR-40 questionnaire was carefully explained to all patients to provide a proper understanding of all issues. The questionnaire evaluates five components of patient recovery: physical comfort (12 questions), physical independence (five questions), emotional state (nine questions), psychological support (seven questions), and pain (seven questions). The sum of the individual components generates an aggregate score. The values obtained from the sum of the QoR-40 range from 40 to 200 , with very poor to outstanding quality of recovery, respectively. This tool has been previously validated in the Portuguese language. ${ }^{12,13}$

The primary end point of the present study was the QoR40 aggregate score at 24 hours. A sample of 25 subjects per group was estimated to achieve $90 \%$ power to detect a 10-point difference in the QoR-40 scores aggregated for the two study groups to be compared using a 12-point SD. A 10-point difference represented a $15 \%$ improvement in quality of recovery based on previously reported values on the mean and range of the QoR-40 following anesthesia and surgery. ${ }^{14}$ The 12-point SD was consistent with a previous investigation. ${ }^{14}$ Considering possible losses and withdrawals, 70 individuals were randomly assigned to one of two groups.

\section{Statistical analyses}

The Shapiro-Wilk and Kolmogorov-Smirnov tests were used to determine whether the data were normally distributed. Normally distributed continuous data are reported as mean (SD) and were evaluated using a two-sided independent $t$-test for equal variances. Non-normally distributed interval data and ordinal data are reported as median (IQR) and were evaluated using the Mann-Whiney $U$ test. ${ }^{15-17}$ Categorical variables are presented as counts (percentages) and were evaluated using the Fisher's exact test. A nonparametric correlation between opioid consumption and global quality of recovery was performed using the Spearman's rho correlation coefficient. The criterion for rejection of the null hypothesis was a two-tailed $P$-value of $<0.05$ for the primary outcome. For secondary outcomes, a two-tailed $P$-value of $<0.001$ was used to reduce type I errors. Statistical analysis was performed using The R Project for Statistical Computing version 3.3.1 (Copyright [C] 1989, 1991; Free Software Foundation, Inc.)

\section{Results}

A flow diagram of the study is presented in Figure 1. Patients were enrolled in the study from July 2016 to November 2016. The research design involved 70 individuals who were randomized; 60 patients completed the study (Figure 1). Six patients requested withdrawal from the study because they were not comfortable with using a new medication or participating in a study, fearing possible adverse effects of the drug. There were no differences in baseline characteristics or surgical factors between the two groups (Table 1). There was no difference in the quality of postoperative recovery assessed according to the QoR-40, between the control and pregabalin groups. The mean (SD) QoR-40 scores were 183.7 (9) vs 182.1 (12) in the placebo and pregabalin groups, respectively (mean difference $=1.6,95 \% \mathrm{CI}-7.36$ to $4.2, P=0.59$ ). There was no difference in length of hospital stay between the two groups (Table 2).

The evaluation of individual QoR-40 subcomponents is presented in Table 3. There was no difference between the QoR-40 domains between the placebo and pregabalin groups assessed by the questionnaire 24 hours after surgery.

There were no significant differences in pain scores between the pregabalin and placebo groups at rest or after coughing at all time points (Table 4). Similarly, there was no reduction in the total consumption of opioids (morphine), both in the PACU and in the 24 hours period of hospitalization in the ward (Table 4). The mean total time to discharge from the PACU was not reduced by the use of pregabalin compared with the control group (84 [31] minutes vs 90.5 [43] minutes, respectively [mean difference $=6.5,95 \%$ CI $72-106, P=0.50$ ]). There was no significant difference in nausea and vomiting between the pregabalin and placebo groups (Table 4). No adverse events, such as excessive drowsiness, sedation, or allergic reactions to pregabalin, were recorded in the present study.

\section{Discussion}

In our study, we found no postoperative analgesic effect from a single oral dose of $75 \mathrm{mg}$ pregabalin compared with placebo, which was administered 1 hour before non-laparoscopic bariatric surgery. There were no significant differences in pain scores between the pregabalin and placebo groups at rest or after coughing at all time points. Similarly, there was no reduction in the total consumption of opioids (morphine), both in the PACU and in the 24-hour period of hospitalization on the ward.

Concern surrounding the quality of anesthesia care has become of great importance in anesthetic practice. For more than 2 decades, researchers have studied outcomes and quality indicators in anesthesia to improve the safety and practice of the specialty. ${ }^{10}$

Myles et al ${ }^{18}$ proposed a more complete model for the evaluation of the quality of anesthetic recovery when they 


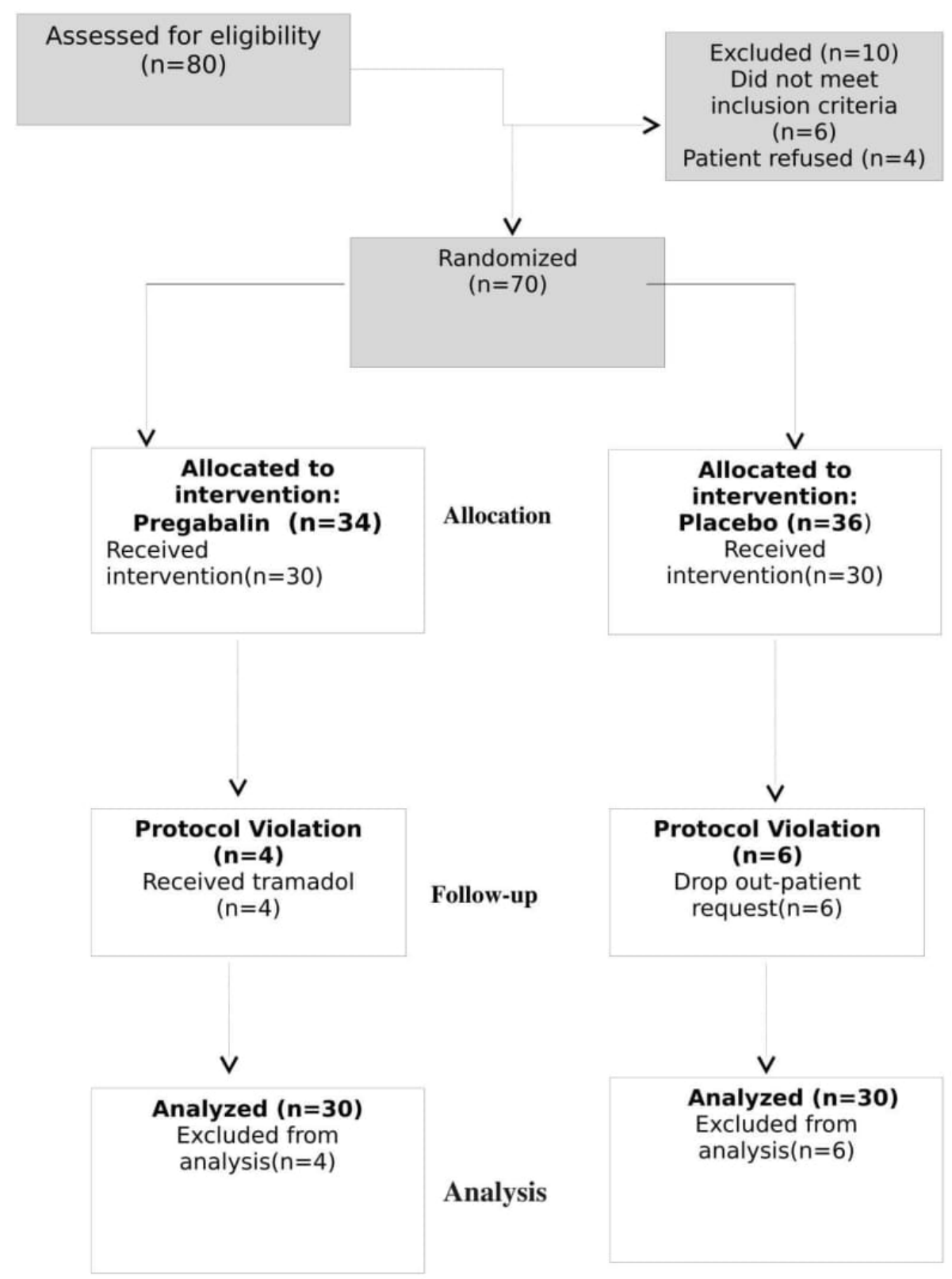

Figure I CONSORT diagram for the study.

Abbreviation: CONSORT, consolidated standards of reporting trials.

studied a questionnaire comprising nine questions that evaluated items such as the ability to breathe, walk, and look after the appearance of nausea or vomiting until the gradation of pain scores experienced by the patients. Subsequent studies have culminated in the development of the QoR-40. Since then, the classifications of patient health status or quality of life have become important outcomes in clinical studies. These outcomes, in part, represent the patient's perception of the outcome of care; this is especially important given that poor quality of recovery often prolongs the duration of stay in the recovery room or delays hospital discharge, both of which have significant implications for the use of health care resources.

Considering the perioperative evaluation in its broadest aspect, the QoR-40 becomes an important tool for determining quality indicators in anesthetic recovery, which includes not only postoperative pain but also components of the patients' autonomy and perception. Some studies that used the QoR-40 demonstrated improvement in scores using several anesthetic strategies. ${ }^{12,14}$

Previous studies assessing postoperative acute pain have demonstrated a beneficial effect of preoperative oral 
pregabalin in reducing pain after surgery and improving the quality of recovery. ${ }^{9}$ A recent study reported that the preoperative administration of pregabalin for a single day $(75 \mathrm{mg}$ twice) proved to be safe, practical, and effective in reducing postoperative pain scores in patients undergoing mastectomy. ${ }^{4}$ Another study reported that the use of a single $300 \mathrm{mg}$ dose of pregabalin administered 1 hour before dacryocystectomy

Table I Baseline characteristics and operative data

\begin{tabular}{|c|c|c|}
\hline Characteristics & Placebo & Pregabalin \\
\hline Age (years) $)^{\mathrm{a}}$ & $38(32-47)$ & $35(29-39)$ \\
\hline Weight $(\mathrm{kg})^{\mathrm{a}}$ & $110(105-119)$ & $110(101-125)$ \\
\hline Height $(\mathrm{cm})^{\mathrm{a}}$ & $165(161-168)$ & $162(157-167)$ \\
\hline BMI $\left(\mathrm{kg} / \mathrm{m}^{2}\right)^{\mathrm{a}}$ & $40.6(39-43.0)$ & $41.1(39.4-47.1)$ \\
\hline Male sex ${ }^{b}$ & $5(16.7 \%)$ & $2(6 \%)$ \\
\hline Associated disease ${ }^{\mathrm{b}}$ & $22(73.3 \%)$ & $18(60.0 \%)$ \\
\hline Hypertension & 17 (56.7\%) & II (36\%) \\
\hline Diabetes mellitus & $4(13.3 \%)$ & $7(23 \%)$ \\
\hline Hepatic steatosis & $2(6.7 \%)$ & $4(13 \%)$ \\
\hline Others & $22(73 \%)$ & $18(60 \%)$ \\
\hline Physical condition (ASA) ${ }^{\mathrm{b}}$ & $\mathrm{I}(3 \%)$ & $2(6 \%)$ \\
\hline I & $25(83 \%)$ & 27 (90\%) \\
\hline$\|$ & $4(13 \%)$ & $1(3 \%)$ \\
\hline III & & \\
\hline Smoking ${ }^{\mathrm{b}}$ & $2(6.7 \%)$ & $0(0 \%)$ \\
\hline Previous surgery ${ }^{b}$ & $24(80 \%)$ & $24(80 \%)$ \\
\hline Previous abdominal surgery ${ }^{\mathrm{b}}$ & $18(60 \%)$ & $19(63 \%)$ \\
\hline Duration of surgery (minutes) & $107(95-125)$ & $117(88$ to 128$)$ \\
\hline Intraoperative hydration ${ }^{\mathrm{a}}$ & 1,500 & 1,500 \\
\hline & $\begin{array}{l}(1,500-2,000 \\
\mathrm{mL})\end{array}$ & $(\mathrm{I}, 500 \mathrm{~mL})$ \\
\hline Intercurrence $\mathrm{b}^{\mathrm{b}}$ & $2(6 \%)$ & $\mathrm{I}(3 \%)$ \\
\hline
\end{tabular}

Notes: ${ }^{a}$ Values expressed as the median and first and third quartiles. ${ }^{b}$ Variables expressed in absolute and relative frequencies.

Abbreviation: ASA, American Society of Anesthesiologists.

Table 2 Quality of recovery measured using the QoR-40 questionnaire (40-200) and hospitalization time according to the intervention group

\begin{tabular}{|l|l|l|l|}
\hline Variable & Placebo & Pregabalin & P-value \\
\hline QoR-40 & $182(13)$ & $183(9)$ & 0.59 \\
Time to hospital discharge (days) & $3(0)$ & $3(0)$ & 1.00 \\
\hline
\end{tabular}

Notes: ${ }^{2}$ Values are expressed as mean and SD. Q०R-40, Quality of Recovery, with 40 questions about the quality of postanesthetic recovery. Higher values indicate a greater degree of satisfaction. was able to decrease the intensity of pain and reduce the amount of opioids needed, as well as nausea and vomiting. ${ }^{19}$ A systematic review and meta-analysis reported that pregabalin improved postoperative analgesia compared with placebo at the expense of increased increases in side effects such as sedation and visual disturbances. ${ }^{20}$ In a meta-analysis, Zhang et al reported that the perioperative administration of pregabalin had a significant opioid-sparing effect in the first 24 hours after surgery. Pregabalin reduced postoperative vomiting, whereas visual disturbance was more common with pregabalin administration. ${ }^{21}$

There are, however, other studies that investigated the postoperative analgesic efficacy of pregabalin and found variable results. ${ }^{22,23}$ A randomized, placebo-controlled trial reported that a single preoperative dose of $100 \mathrm{mg}$ pregabalin did not reduce acute pain or improve recovery after uterine surgery. The authors assigned the lack of result to the subtherapeutic dose of pregabalin administered, as well as the type of surgery and pain mechanism. ${ }^{7}$ Another clinical trial reported no benefit with the use of perioperative pregabalin for reduction of referred pain in the shoulder region after laparoscopic cholecystectomy. ${ }^{24}$

These results are in agreement with those found by Paech et $\mathrm{al}^{7}$ and Singla et $\mathrm{al}^{25}$ who found that perioperative pregabalin had no beneficial effect on postoperative pain scores after elective inguinal hernia repair, elective total knee arthroplasty (TKA), and gynecological surgeries. There was little improvement over placebo in functional-/movement-related pain with $300 \mathrm{mg} /$ day pregabalin in postoperative inguinal hernia repair and post TKA trials. ${ }^{25}$

In our study, we found no postoperative analgesic effect from a single oral dose of $75 \mathrm{mg}$ pregabalin compared with placebo, administered 1 hour before bariatric surgery. These results can be attributed to the use of a strong multimodal analgesic strategy (eg, IV ketoprofen $100 \mathrm{mg}$ every 8 hours and metamizol/dipyrone 2 g every 6 hours), as well as surgical wound infiltration, a result compatible with other studies. $^{25}$

Table 3 Subcomponents of the QoR-40 questionnaire by study groups evaluated 24 hours after surgery

\begin{tabular}{|l|l|l|l|l|l|l|l|}
\hline Variables & \multicolumn{4}{l|}{ Placebo $(\mathbf{n}=\mathbf{3 0})$} & \multicolumn{2}{l|}{ Pregabalin $\mathbf{( n = 3 0 )}$} \\
\cline { 2 - 8 } & Median & First quartile & Third quartile & Median & First quartile & Third quartile & P-value \\
\hline Physical comfort & 54 & 49 & 58 & 53 & 50 & 57 & 0.64 \\
Physical independence & 25 & 24 & 25 & 25 & 23 & 25 & 0.43 \\
Support & 35 & 31 & 35 & 35 & 32 & 35 & 0.63 \\
Emotional status & 40 & 33 & 45 & 42 & 36 & 44 & 35 \\
Pain & 33 & 31 & 34 & 33 & 32 & 0.57 & \\
\hline
\end{tabular}

Note: QoR-40: Quality of Recovery, with 40 questions about the quality of postanesthetic recovery. 
Table 4 Occurrence of pain ${ }^{a}$, nausea, vomiting, and morphine consumption in the postoperative period according to the intervention group

\begin{tabular}{|c|c|c|c|}
\hline Time point & Placebo & Pregabalin & $P$-value \\
\hline End of surgery ${ }^{b}$ & $0.7(0-1.5)$ & $0.5(0-1.1)$ & 0.67 \\
\hline Admission to the $\mathrm{PACU}$ at rest ${ }^{\mathrm{b}}$ & $1.7(0.7-2.6)$ & $2.3(1.3-3.3)$ & 0.35 \\
\hline Admission to the PACU with cough stimulus ${ }^{\mathrm{b}}$ & $1.9(0.9-2.9)$ & $2.7(1.6-3.9)$ & 0.26 \\
\hline After I hour in the PACU at rest ${ }^{\mathrm{b}}$ & $3.7(2.5-4.9)$ & $3.5(2.4-4.3)$ & 0.74 \\
\hline After I hour in the PACU with cough stimulus ${ }^{b}$ & $4.3(3.1-5.4)$ & $4.1(3.2-5)$ & 0.85 \\
\hline 24 hours after surgery, at rest ${ }^{b}$ & $1.8(1.1-2.6)$ & $\mathrm{I}(0.5-1.5)$ & 0.06 \\
\hline 24 hours after surgery, with cough stimulus ${ }^{b}$ & $2.9(2.1-3.6)$ & $2.3(1.4-2.9)$ & 0.15 \\
\hline Morphine use in the PACU & $15(50.0 \%)$ & $18(60.0 \%)$ & 0.43 \\
\hline Time to use morphine in the PACU (minutes) & $11(13-17)$ & $13(7-20)$ & 0.67 \\
\hline Total dose of morphine in the PACU $(\mathrm{mg})^{\mathrm{b}}$ & $3.4(1.7-5 . I)$ & $2.5(1.5-3.5)$ & 0.37 \\
\hline Morphine use on POD I (number of patients) & $5(16.7 \%)$ & $3(10.0 \%)$ & 0.70 \\
\hline Total dose of morphine on POD I (mg) & $0.4(0-0.9)$ & $0.2(0-0.4)$ & 0.3 \\
\hline PACU discharge time (minutes) ${ }^{b}$ & $90(74-106)$ & $84(72-95)$ & 0.5 \\
\hline Nausea in the PACU & $10(33.3 \%)$ & $12(40.0 \%)$ & 0.59 \\
\hline Vomiting in the PACU & $0(0.0 \%)$ & $2(6.7 \%)$ & 0.49 \\
\hline Nausea on POD I ${ }^{c}$ & $6(20.0 \%)$ & $12(40.0 \%)$ & 0.15 \\
\hline Vomiting on POD $\left.\right|^{c}$ & $3(10.0 \%)$ & $6(20.0 \%)$ & 0.47 \\
\hline
\end{tabular}

Notes: aReported unit is based on NRS pain score. ${ }^{b}$ Values are expressed as mean and $95 \% \mathrm{Cl}$. ${ }^{\mathrm{V}}$ alues are expressed in absolute and relative frequencies, number of patients who presented the event.

Abbreviations: PACU, postanesthesia care unit; POD, postoperative day; NRS, numerical rating scale.

It has been demonstrated that high doses of systemic dexamethasone $(0.1 \mathrm{mg} / \mathrm{kg})$ can improve postoperative analgesia in patients undergoing outpatient surgery under general anesthesia. ${ }^{26}$ Patients in the current study received systemic dexamethasone $(4 \mathrm{mg})$ for prophylaxis of nausea and vomiting. It is possible that the concomitant administration of systemic dexamethasone could have a parallel analgesic effect as described in other scientific studies that investigated postoperative pain. ${ }^{27,28}$ On the other hand, some studies have also shown that the use of dexamethasone, at a dose of $4 \mathrm{mg}$, did not reduce postoperative pain in patients undergoing mastectomy. ${ }^{29,30}$

The study by Alimian et al has interestingly demonstrated the analgesic effect of pregabalin $300 \mathrm{mg}$ in bariatric surgery. It is worth noting, however, that it was a nonrandomized study and with a limited number of patients, the authors also did not explore the side effects of this medication at this dosage used. In our study, we used the single dose of $75 \mathrm{mg}$, based on studies with high reproducibility such as the review performed by Mishriky et al, who showed that all dose of pregabalin tested $(<75,100-150$, and $300 \mathrm{mg})$ resulted in opioid sparing at 24 hours after surgery. They also demonstrated that there were no significant differences in acute pain outcomes with pregabalin 100-300 mg between single perioperative dosing regimens.
Limitations of our study include the use of a robust multimodal analgesic strategy that included anti-inflammatory drugs, opioids, and surgical wound infiltration with local anesthetic, which may have contributed to the reduction in the overall incidence of postoperative pain, making it more difficult to detect differences in pain control between the two groups. Furthermore, we could still attribute the failure of our study to demonstrate an improvement in the quality of postoperative recovery to the possible subtherapeutic dose of pregabalin used. These results are in agreement with other studies using pregabalin for the improvement of postoperative pain. ${ }^{7,23,30,31}$ However, higher doses of pregabalin ( $>300$ $\mathrm{mg}$ ) have been associated with a higher incidence of side effects, such as dizziness and drowsiness, despite evidence of a reduction in opioid consumption in the postoperative period. ${ }^{32,33}$ We did not assess the incidence of chronic pain in our study; therefore, we could not evaluate the effect of pregabalin on chronic pain.

\section{Conclusion}

We demonstrated that a single preoperative dose of $75 \mathrm{mg}$ pregabalin administered to patients who underwent open bariatric surgery did not improve pain control, quality of postoperative recovery, or result in a reduction in opioid 
consumption when compared with placebo. Other clinical trials are required to define the effective dose and duration of the perioperative pregabalin regimen to determine the potential benefits of postoperative pain treatment in these patients.

\section{Author contributions}

All authors contributed toward data analysis, drafting and revising the paper and agree to be accountable for all aspects of the work.

\section{Disclosure}

The authors report no conflicts of interest in this work.

\section{References}

1. Noria SF, Grantcharov T. Biological effects of bariatric surgery on obesity-related comorbidities. Can J Surg. 2013;56(1):47-57.

2. Elrazek AE, Elbanna AE, Bilasy SE. Medical management of patients after bariatric surgery: Principles and guidelines. World J Gastrointest Surg. 2014;6(11):220-228.

3. Hassani V, Pazouki A, Nikoubakht N, Chaichian S, Sayarifard A, Shakib Khankandi A. The effect of gabapentin on reducing pain after laparoscopic gastric bypass surgery in patients with morbid obesity: a randomized clinical trial. Anesth Pain Med. 2015;5(1):e22372.

4. Kim SY, Song JW, Park B, Park S, An YJ, Shim YH. Pregabalin reduces post-operative pain after mastectomy: a double-blind, randomized, placebo-controlled study. Acta Anaesthesiol Scand. 2011;55(3): 290-296.

5. Kehlet H, Dahl JB. The value of "multimodal" or "balanced analgesia" in postoperative pain treatment. Anesth Analg. 1993;77(5): 1048-1056.

6. Gajraj NM. Pregabalin: its pharmacology and use in pain management. Anesth Analg. 2007;105(6):1805-1815.

7. Paech MJ, Goy R, Chua S, Scott K, Christmas T, Doherty DA. A randomized, placebo-controlled trial of preoperative oral pregabalin for postoperative pain relief after minor gynecological surgery. Anesth Analg. 2007;105(5):1449-1453.

8. Fawzi H, El-Tohamy S. Effect of perioperative oral pregabalin on the incidence of post-thoracotomy pain syndrome. Ain-Shams J Anaesthesiol. 2014;7(2):143.

9. Lam D, Choi SW, Wong SS, Irwin MG, Cheung CW. Efficacy of pregabalin in acute postoperative pain under different surgical categories: a meta-analysis. Medicine (Baltimore). 2015;94(46):e1944.

10. Myles PS, Weitkamp B, Jones K, Melick J, Hensen S. Validity and reliability of a postoperative quality of recovery score: the QoR-40. $\mathrm{Br}$ J Anaesth. 2000;84(1):11-15.

11. Gornall BF, Myles PS, Smith CL, et al. Measurement of quality of recovery using the QoR-40: a quantitative systematic review. $\mathrm{Br} J$ Anaesth. 2013;111(2):161-169.

12. Moro ET, Leme FC, Noronha BR, Saraiva GF, de Matos Leite NV, Navarro LH. Quality of recovery from anesthesia of patients undergoing balanced or total intravenous general anesthesia. Prospective randomized clinical trial. J Clin Anesth. 2016;35:369-375.

13. Eduardo AHA, Santos CB, Carvalho AMP, Carvalho E. [Validation of the Brazilian version of the questionnaire. Quality of Recovery - 40 Items]. Validação da versão brasileira do questionário. Quality of Recovery - 40 Items. Acta Paul Enfern. 2016;29(3):253-259.
14. Catro-Alves LJ, De Azevedo VL, De Freitas Braga TF, Goncalves AC, De Oliveira GS Jr. The effect of neuraxial versus general anesthesia techniques on postoperative quality of recovery and analgesia after abdominal hysterectomy: a prospective, randomized, controlled trial. Anesth Analg. 2011;113(6):1480-1486.

15. Divine G, Norton HJ, Hunt R, Dienemann J. Statistical grand rounds: a review of analysis and sample size calculation considerations for Wilcoxon tests. Anesth Analg. 2013;117(3):699-710.

16. Dexter F. Wilcoxon-Mann-Whitney test used for data that are not normally distributed. Anesth Analg. 2013;117(3):537-538.

17. Lunneborg C. Data Analysis by Resampling: Concepts and Applications, 1st ed. Chap 4 Washington: Brooks/Cole; 2000:76-90.

18. Myles PS, Hunt JO, Nightingale CE, et al. Development and psychometric testing of a quality of recovery score after general anesthesia and surgery in adults. Anesth Analg. 1999;88(1):83-90.

19. Alimian M, Imani F, Hassani V, Rahimzadeh P, Sharifian M, Safari S. Effects of single-dose pregabalin on postoperative pain in dacryocystorhinostomy surgery. Anesth Pain Med. 2012;2(2):72-76.

20. Mishriky BM, Waldron NH, Habib AS. Impact of pregabalin on acute and persistent postoperative pain: a systematic review and meta-analysis. Br J Anaesth. 2015;114(1):10-31.

21. Zhang J, Ho KY, Wang Y. Efficacy of pregabalin in acute postoperative pain: a meta-analysis. Br J Anaesth. 2011;106(4):454-462.

22. Park SS, Kim DH, Nam IC, Lee IH, Hwang JW. The effectiveness of pregabalin for post-tonsillectomy pain control: a randomized controlled trial. PLoS One. 2015;10(2): 0117161.

23. Jokela R, Ahonen J, Tallgren M, Haanpää M, Korttila K. Premedication with pregabalin 75 or $150 \mathrm{mg}$ with ibuprofen to control pain after day-case gynaecological laparoscopic surgery. Br JAnaesth. 2008;100(6):834-840.

24. Chang SH, Lee HW, Kim HK, Kim SH, Kim DK. An evaluation of perioperative pregabalin for prevention and attenuation of postoperative shoulder pain after laparoscopic cholecystectomy. Anesth Analg. 2009;109(4):1284-1286.

25. Singla NK, Chelly JE, Lionberger DR, et al. Pregabalin for the treatment of postoperative pain: results from three controlled trials using different surgical models. J Pain Res. 2015;8:9-20.

26. De Oliveira GS Jr, Ahmad S, Fitzgerald PC, et al. Dose ranging study on the effect of preoperative dexamethasone on postoperative quality of recovery and opioid consumption after ambulatory gynaecological surgery. Br J Anaesth. 2011;107(3):362-371.

27. Shah SA, Khan I, Shah HS. Effectiveness of submucosal dexamethasone to control postoperative pain \& swelling in apicectomy of maxillary anterior teeth. Int J Health Sci (Qassim). 2011;5(2):156-165.

28. Waldron NH, Jones CA, Gan TJ, Allen TK, Habib AS. Impact of perioperative dexamethasone on postoperative analgesia and side-effects: systematic review and meta-analysis. Br J Anaesth. 2013;110(2):191-200.

29. Gómez-Hernández J, Orozco-Alatorre AL, Domínguez-Contreras M, et al. Preoperative dexamethasone reduces postoperative pain, nausea and vomiting following mastectomy for breast cancer. BMC Cancer. 2010;10:692.

30. Fujii Y, Nakayama M. Reduction of postoperative nausea and vomiting and analgesic requirement with dexamethasone in women undergoing general anesthesia for mastectomy. Breast J. 2007;13(6):564-56; retraction published online.

31. Alimian M, Imani F, Faiz SH, Pournajafian A, Navadegi SF, Safari S. Effect of oral pregabalin premedication on post-operative pain in laparoscopic gastric bypass surgery. Anesth Pain Med. 2012;2(1):12-16.

32. Jokela R, Ahonen J, Tallgren M, Haanpää M, Korttila K. A randomized controlled trial of perioperative administration of pregabalin for pain after laparoscopic hysterectomy. Pain. 2008;134(1-2):106-112.

33. Kim SY, Jeong JJ, Chung WY, Kim HJ, Nam KH, Shim YH. Perioperative administration of pregabalin for pain after robot-assisted endoscopic thyroidectomy: a randomized clinical trial. Surg Endosc. 2010;24(11):2776-2781. 


\section{Supplementary material}

Date:

\section{Part A}

How have you been feeling in the last day? (circle one)

\begin{tabular}{|c|c|c|c|c|c|}
\hline CONFORT & $\begin{array}{l}\text { None of the } \\
\text { time }\end{array}$ & $\begin{array}{l}\text { Some of the } \\
\text { time }\end{array}$ & Usualy & $\begin{array}{l}\text { Mosto of the } \\
\text { time }\end{array}$ & $\begin{array}{l}\text { All of } \\
\text { the time }\end{array}$ \\
\hline \multicolumn{6}{|l|}{ CONFORT } \\
\hline Able to breathe easily & I & 2 & 3 & 4 & 5 \\
\hline Have had a good sleep & I & 2 & 3 & 4 & 5 \\
\hline Been able to enjoy food & I & 2 & 3 & 4 & 5 \\
\hline Feel rested & 1 & 2 & 3 & 4 & 5 \\
\hline \multicolumn{6}{|l|}{ EMOTIONS } \\
\hline Have a feeling of general well-being & I & 2 & 3 & 4 & 5 \\
\hline Feeling in control & I & 2 & 3 & 4 & 5 \\
\hline Feeling comfortable & $\mathrm{I}$ & 2 & 3 & 4 & 5 \\
\hline \multicolumn{6}{|l|}{ PHYSICAL } \\
\hline Have normal speech & I & 2 & 3 & 4 & 5 \\
\hline Able to wash, brush teeth, shave & I & 2 & 3 & 4 & 5 \\
\hline Able to look after your own appearance & $\mathrm{I}$ & 2 & 3 & 4 & 5 \\
\hline Able to write & I & 2 & 3 & 4 & 5 \\
\hline Able to return to work/usual home activities & $\mathrm{I}$ & 2 & 3 & 4 & 5 \\
\hline \multicolumn{6}{|l|}{ SUPPORT } \\
\hline Been able to communicate with MD & I & 2 & 3 & 4 & 5 \\
\hline Able to communicate with family/friends & I & 2 & 3 & 4 & 5 \\
\hline Able to communicate with visiting health care worker & I & 2 & 3 & 4 & 5 \\
\hline Having support from family/friends & 1 & 2 & 3 & 4 & 5 \\
\hline Getting support from visiting healthcare worker & I & 2 & 3 & 4 & 5 \\
\hline Able to understand instructions and advice & I & 2 & 3 & 4 & 5 \\
\hline
\end{tabular}

Figure SI (Continued) 


\section{PART B}

Have you had any of the following in the last 24 hours?

\begin{tabular}{|c|c|c|c|c|c|}
\hline & $\begin{array}{l}\text { None of the } \\
\text { time }\end{array}$ & $\begin{array}{l}\text { Some of the } \\
\text { time }\end{array}$ & Usually & $\begin{array}{l}\text { Most of the } \\
\text { time }\end{array}$ & $\begin{array}{l}\text { All of the } \\
\text { time }\end{array}$ \\
\hline \multicolumn{6}{|l|}{ COMFORT } \\
\hline Nausea & 5 & 4 & 3 & 2 & I \\
\hline Vomiting & 5 & 4 & 3 & 2 & I \\
\hline Retching & 5 & 4 & 3 & 2 & 1 \\
\hline Feeling restless & 5 & 4 & 3 & 2 & 1 \\
\hline Shaking/twitching & 5 & 4 & 3 & 2 & 1 \\
\hline Shivering & 5 & 4 & 3 & 2 & I \\
\hline Feeling cold & 5 & 4 & 3 & 2 & 1 \\
\hline Feeling dizzy & 5 & 4 & 3 & 2 & 1 \\
\hline \multicolumn{6}{|l|}{ EMOTIONS } \\
\hline Had bad dreams & 5 & 4 & 3 & 2 & 1 \\
\hline Feeling anxious & 5 & 4 & 3 & 2 & 1 \\
\hline Feeling angry & 5 & 4 & 3 & 2 & 1 \\
\hline Feeling depressed & 5 & 4 & 3 & 2 & I \\
\hline Feeling alone & 5 & 4 & 3 & 2 & I \\
\hline Had difficulty falling asleep & 5 & 4 & 3 & 2 & 1 \\
\hline \multicolumn{6}{|l|}{ PATIENT } \\
\hline Feeling confused & 5 & 4 & 3 & 2 & I \\
\hline \multicolumn{6}{|l|}{ PAIN } \\
\hline Moderate pain & 5 & 4 & 3 & 2 & I \\
\hline Severe pain & 5 & 4 & 3 & 2 & I \\
\hline Headache & 5 & 4 & 3 & 2 & 1 \\
\hline Muscle Pain & 5 & 4 & 3 & 2 & I \\
\hline Backache & 5 & 4 & 3 & 2 & $\mathrm{I}$ \\
\hline Sore throat & 5 & 4 & 3 & 2 & I \\
\hline Sore mouth & 5 & 4 & 3 & 2 & I \\
\hline
\end{tabular}

Date:

Figure SI QoR-40.

Note: QoR-40: Quality of Recovery, with 40 questions about the quality of postanesthetic recovery.

Journal of Pain Research

\section{Publish your work in this journal}

The Journal of Pain Research is an international, peer reviewed, open access, online journal that welcomes laboratory and clinical findings in the fields of pain research and the prevention and management of pain. Original research, reviews, symposium reports, hypothesis formation and commentaries are all considered for publication.

\section{Dovepress}

The manuscript management system is completely online and includes a very quick and fair peer-review system, which is all easy to use. Visit http://www.dovepress.com/testimonials.php to read real quotes from published authors. 